\author{
Military Technical College \\ Kobry El-Kobbah, \\ Cairo, Egypt.
}

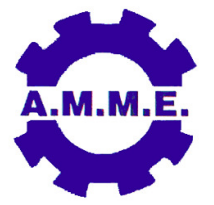
$17^{\text {th }}$ International Conference on Applied Mechanics and Mechanical Engineering.

\title{
THE EFFECT OF AGING TREATMENT ON THE FRICTION-STIR- PROCESSED AA7075 ALLOY WITH AND WITHOUT SURFACE NANO-DISPERSION
}

\author{
M. Refat ${ }^{a}$, A. Elashery ${ }^{b}$, M.M.Z. Ahmed ${ }^{c}$ and I. El-Mahallawi ${ }^{b, d}$
}

\begin{abstract}
Friction stir processing (FSP) is a novel processing technique that is gaining wide recognition for manufacturing nano-dispersed surfaces, which are of high specific strength, hardness, and resistance to wear and corrosion. Herein, four-passes FSP were applied on aluminum alloy 7075 (AA7075) $O$ with and without the addition of alumina nanoparticles (Al2O3) of average size $\sim 40 \mathrm{~nm}$. All FSP parameters were constant at $40 \mathrm{~mm} / \mathrm{min}$ transverse speed, $500 \mathrm{rpm}$ and tilt angle of $3^{\circ}$. FSP rotation direction was reversed every two passes. The friction stir processed materials were sectioned and solution treated at $515^{\circ} \mathrm{C}$ for $1.5 \mathrm{hrs}$, followed by age hardening at $120^{\circ} \mathrm{C}$ for $12,24,46,48$ and $60 \mathrm{hrs}$. The effect of heat treatment regimes on microstructure, hardness and toughness was examined, as well as the fracture mode. The new friction-stir processed surfaces without and with nanodispersion showed enhancement in the hardness of the surface of the AA7075-O material (65 $\mathrm{HV}$ ) to almost a double (100 and $140 \mathrm{HV}$ ) after 4 passes FSP without and with incorporating nano-alumina particles, respectively. After $48 \mathrm{hrs}$ aging at $120^{\circ} \mathrm{C}$ a significant enhancement in impact toughness was achieved for both the friction stir processed without and with nanodispersion (181 and 134J, respectively), compared to the reference material AA7075 in T6 condition (104J).
\end{abstract}

\section{KEY WORDS}

AA7075, Friction stir processing, Hardness, Toughness, Microstructure, Heat treatment.

a Department of Mechanical Engineering, Faculty of Engineering, The British University in Egypt, Cairo, Egypt, currently Egyptian Vehicles Manufacturing Company, (Hyundai-Egypt).

b Department of Metallurgy, Faculty of Engineering, Cairo University, Cairo, Egypt.

c Department of Metallurgical \& Materials Engineering, Faculty of petroleum \& Mining Engineering, Suez University, 43721 Suez, Egypt.

d Adjunct Professor, the British University in Egypt. 


\section{INTRODUCTION}

Friction stir processing (FSP) is a recent surface engineering processing technique that may be utilized to various metals such as aluminum, titanium, magnesium, copper, nickel and iron-based alloys [1,2]. The main concept is based on the friction stir welding (FSW) idea that was established in 1991 by the Welding Institute (TWI) in the United Kingdom [3], where a durable rotating tool with particularly designed shoulder and pin is plunged between the edges of the material, resulting intense plastic deformation at elevated temperature and bonding of the joint.

FSP has many advantages compared to other surface modification techniques based on liquid and fusion processes, since the latter cannot avoid interfacial reactions between the metal matrix and reinforcement used. Such interactions may lead to defects including pin holes, segregation, shrinkage cavity, grain coursing and pores $[4,5]$. Mishra [1] has explained the main advantages of using FSP as a surface modification technique to be: 1) the FSP is carried out in solid state, so, interfacial reaction and formation of detrimental phases are avoided, 2) the FSP results in significant grain refinement in the surface layer, since the wrought microstructure is desirable for enhanced fracture properties as compared with the solidified microstructure that results from laser processing or high-energy electron beam irradiation.

The process has been also applied to the manufacture of surface composites by incorporating nano-sized alumina into AA6082 aluminium alloy and for the uniform distribution of $\mathrm{SiC}$ particles into a surface layer of A1050-H24 alloy [5, 6]. The new surfaces showed defect free interfaces and the perfect bonding between the substrate and the surface composite. Mahmoud et al showed the effect of tool-probe size and shape on the structure and properties of the surface composite [7].

One of the important applications that may benefit from this technology is armored vehicles. Though steel is the strongest competitor in military applications due to its high strength, hardness, energy absorbing properties, and greater notch toughness, aluminum is still the future element for those applications where enhanced mobility with safety are the main requirements [8-10]. However Backman et al. and Corbett et al. have shown that aluminium alloys have special properties that can limit their usage as armor material specifically: lower young's modulus, lower sensitivity to strain rate, and lower melting point [5,11-12].

The idea of FSP is very simple and is based on the main concept of friction stir welding (FSW) where a rotating tool is integrated in a monolithic plate to obtain a microstructure modification which is used for particular feature enhancement. In a previous study by the authors [13] in which AA7075-O /nano-alumina composite was developed using FSP, significant increase in surface hardness was only found to occur after four passes in the un-heat treated condition. It was also observed that, heat treatment $(\mathrm{HT})$ of the nano-surface composite resulted in lower hardness in the processed region relative to the base material at the same HT condition. At that stage, this was attributed to the existence of nano particles that delays the hardening effect of T6 heat treatment in the processed region. 
Thus, the aim of the current work was to study the effect of heat treatment on the hardening behavior of the friction stir processed AA7075-O with and without the addition of nano particles. In this work the FSP parameters for the stirring passes were reduced to $500 \mathrm{rpm}$ tool rotation rate, $40 \mathrm{~mm} / \mathrm{min}$ - traverse speed and $3^{\circ}$ tool tilt angle, to avoid the cavitation effect which was observed in the previous work [13]. The processing direction was also altered in this work, where the advancing side of the previous pass was converted into a retreating side in the next pass and viceversa. The aim of this work is to investigate the effect of nano alumina dispersion and friction stir processing on the microstrcture, hardness and impact toughness of AA7075 for different aging-time periods.

\section{EXPERIMENTAL WORK}

The material used in this study is Aluminum alloy 7075 (AA7075) sheet plate. AA7075 was received in T6 temper condition with a measured Vickers hardness number of $177 \mathrm{HV}$. The sheet plates of AA7075-T6 were annealed to have it in the $O$ temper condition of measured Vickers hardness number $64 \mathrm{HV}$. Al2O3 nanoparticles with average size of $40 \mathrm{~nm}$ as the reinforcements and AA7075-O were used as a metal matrix.

Work pieces were prepared with a length of $200 \mathrm{~mm}$ and width of $150 \mathrm{~mm}$. A groove was machined through the surface of the AA7075 with a depth of $4.5 \mathrm{~mm}$ and $1 \mathrm{~mm}$ width and along the whole length of the piece. Al2O3 nanoparticles were packed into the groove after closing the sides of the groove to prevent escaping of the nanoparticles during friction stir processing (FSP). Then a probeless tool of $19 \mathrm{~mm}$ shoulder diameter was used for top closing of the groove after packing of the nanoparticles at the same FSP parameters used.

FSP using the conventional FSP tool made of $\mathrm{H} 13$ tool steel, which was heat treated to obtain 55HRC hardness was carried out. The FSP tool dimensions were of $19 \mathrm{~mm}$ diameter shoulder, $6.2 \mathrm{~mm}$ probe and $5.3 \mathrm{~mm}$ probe length. FSP was carried out at constant traverse speed of $40 \mathrm{~mm} / \mathrm{min}$, rotation rate $500 \mathrm{rpm}$ and tool tilt angle was set at $3^{\circ}$. The plate was subjected to 4 passes based on results found by previous work by the authors [13]. The advancing side of the previous pass converted into retreating side in the next pass and vice-versa. After FSP the material of $O$ temper condition was age hardened to T6 temper condition by solution treatment at $515^{\circ} \mathrm{C}$ and water quenching followed by age hardening at $120{ }^{\circ} \mathrm{C}$ for $12 \mathrm{hrs}, 24 \mathrm{hrs}, 36 \mathrm{hrs}$, $48 \mathrm{hrs}$ and $60 \mathrm{hrs}$. Figure 1 shows a shematic presentation of the process.

After the manufacturing of the new nano- surface dispersed material, samples from the different friction stir processed sample were cut perpendicular to the processing direction. The samples were then mounted using hot mounting press and prepared according to the standard preparation technique starting with grinding of different grades up to 1200 size paper and then mechanically polished using $6 \mu \mathrm{m}, 1 \mu \mathrm{m}$

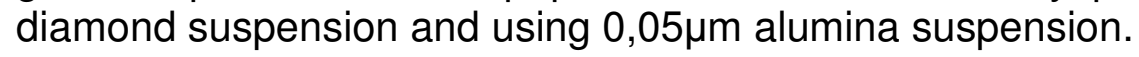

A number of material characterization tests were carried out including: optical macrography, micrography, hardness, and impact toughness. After FSP and heat treatment sample from each condition were cut perpendicular to the processing 
direction. The samples were prepared for metallographic examination according to the standard preparation methods. Grinding was done using different SiC papers with grades up to 2000 size paper, followed by mechanical polishing using $1 \mu \mathrm{m}$ diamond suspension and using $0.3 \mu \mathrm{m}$ alumina suspension. The samples were examined using Olympus optical microscopy. After etching using diluted keller's reagent of chemical composition ( $190 \mathrm{ml}$ distilled water, $3 \mathrm{ml} \mathrm{HNO}, 5 \mathrm{ml} \mathrm{HCL}$ and $2 \mathrm{ml} \mathrm{HF}$ ) for $30 \mathrm{sec}$.

The microhardness measurements were made on a Vickers microhardness testing machine where a number of at least 20 readings were taken at $1 \mathrm{~mm}$ intervals, using load of $1 \mathrm{~kg}$ for $15 \mathrm{~s}$ dwell time through the whole processed zone. The impact toughness testing was done on an JB-W500 Impact Testing Machine, using a $15 \mathrm{~kg}$ Pendulum, on notch-less specimens of $10 \times 10 \times 60 \mathrm{~mm}$ dimensions. The test was conducted so that the pendulum hits the friction stir processed surface at a point perpendicular to the nugget.

\section{RESULTS AND DISCUSSION}

\section{Optical Macrographs}

The optical macrographs of the as friction stir processed AA7075-O without nano alumina additions, without (a) and with (b) T6 heat treatment are shown in Figure 2 (a, b). Also Figures 2 (c, d) show the optical macrographs of the as friction stir processed AA7075-O with nano alumina additions without (c) and with (d) T6 heat treatment. FSP was carried out for 4 passes using 500rpm rotation rate and $40 \mathrm{~mm} / \mathrm{min}$ traverse speed two passes in clockwise direction and two passes in counterclockwise direction. The typical nugget (NG) shape of such a friction stir processed material is observed in a, while typical as rolled textured macrostructure appears in the base metal zone. After addition of the nano alumina particles it can be observed from the macrograph in $\mathrm{c}$ that some agglomerates of nano particles exist near the top surface of the NG in addition to some small voids near the base of the NG.

\section{Optical Microstructure}

Figure 3 shows the microstructure of the stirred zone for the friction stir processed sample with nano alumina additions inside the NG region before heat treatment. It can be seen from Fig. 3 that the nano particles (after 4passes) are still not uniformly distributed across the NG; as some areas have agglomerates, while others are almost free of nanoparticles. Generally, the structure of this alloy consists of a mixture of $\alpha$ phase (solid solution of $\mathrm{Zn}$ in Al) and intermetallic second phase. These intermetallic constituents are irregularly shaped and form during solidification according to the presence of $\mathrm{Fe}, \mathrm{Mn}$ and $\mathrm{Si}$ with $\mathrm{Cu}$. Rolling and extrusion causes the breakup and alignment of the constituent particles into bands within the alloy [14].

Figure 4 shows a typical microstructure along the cross section of the friction stir processed zone of the monolithic AA7075 alloy after 24hrs aging, where the stirred zone is shown in Fig. 4c, d and e, and the TMAZ is shown in Fig. 4a and b. It is 
revealed from Fig. 4 that for the monolithic samples (Fig. 4c and e) a refined equiaxed structure $(\cong 14-27 \mu \mathrm{m})$ is present at the top of the nugget, where the grains have undergone dynamic recrystallization due to the heat generated and the sever plastic deformation during the FSP process. A significant density of small precipitates exists in the NZ. The region just at the bottom of the SZ shows courser grains, where the demarcation between the NZ and the original elongated pancake-shaped grains appear. The finer grain sizes at the top of the NZ are explained to be a result of this zone being exposed to higher deformation accompanied with more frictional heat, as it is closer to the tool compared to the position at the bottom of the NZ, this effect promotes conditions leading to dynamic recrystallization

Figure 5 shows a typical microstructure along the cross section of the friction stir processed zone of the nanodispersed AA7075 alloy after 24hrs aging, where the stirred zone is shown in Fig. 5c, d and e, and the TMAZ is shown in Fig. 5a and 5b. In Fig. $5 \mathrm{c}$, the $\mathrm{NZ}$ is revealed with equi-axed grains (in the order of $\cong 6-12 \mu \mathrm{m}$ ). This is explained by the role of nanoparticles on pinning the grain boundaries and reducing their mobility. Fig. 5a shows the transition from NZ to TMAZ in the advancing side. Coarser precipitates are observed in the TMAZ compared to the NZ, which are most likely resulting from growth of original precipitates. The highgenerated heat in the NZ, during friction stir processing stage, leads to the dissolution of the original precipitates and finer precipitates form later in this zone during the aging treatment.

Two main differences are observed between figures 4 and 5 . The first difference is that the structure is more refined after adding nanoparticles $(\cong 14-27 \mu \mathrm{m}$ for the monolithic alloy, versus $\cong 6-12 \mu \mathrm{m}$ for the alloy with nanoparticles). The second difference is the extension of the refined zone deeper below the surface for the nanoparticle-reinforced material compared to the monolithic alloy, which showed abnormal grain growth just below the friction-stir-processed surface.

\section{Vickers Hardness}

For the sake of understanding the effect of nanodispersion on the surface hardness after T6 heat treatment, the hardness was measured at the same position for all samples and after all aging times. Figure 6 shows the Vickers hardness collective curves measured near the top surface of the friction stir processed materials at an interval of $1 \mathrm{~mm}$ across the transverse cross section, for all conditions. The samples were subjected to solution treatment at $515 \mathrm{C}$ for $1.5 \mathrm{hrs}$ and then aged for the indicated times.

It can be observed that in the case of, as friction stir processed material without any heat treatment the effect of nano-alumina particles is significant in hardness increase relative to the one without nanodispersion. However, applying the heat treatment regime of solution treatment at $515^{\circ} \mathrm{C}$ for $1.5 \mathrm{hrs}$ and age hardening at $120^{\circ} \mathrm{C}$ for different times has resulted in a slighter difference in the hardness between the two cases with and without nano particles additions, though the scatter in the hardness results across the tested region has decreased. After friction stir processing and before solution treatment, the main active strengthening mechanisms for the monolithic alloy are those affected by the induced stresses resulting from the severe 
plastic deformation and affecting the dynamic recrystallization occurring simultanuously, as well as the redistribution of the intermetallic precipitates. In addition to those, nanoparticles dispersion adds extra strengthening for the nanostrengthened alloy. After solution treatment, the induced stresses are released and the intermetallic precipitates may dissolve. Aging will cause the precipitates to reform. This suggests that adding nano particles during FSP will tend to conceal or suppress the effect of heat treatment, probably due to the formation of softened regions in the treated zones or due to the early formation of the more stable precipitates during friction stir processing, induced by the temperature rise due to the induced frictional heat during friction stir processing. It may be necessary to mention at this point that the main hardening effect obtained in 7075 by T6 heat treatment is due to the formation of G-P zones. G-P zones are metastable, coherent solute clusters of Zn, $\mathrm{Mg}$ and $\mathrm{Cu}$. The metastable $\eta^{\prime}, \mathrm{MgZn}_{2}$ or more correctly $\mathrm{Mg}(\mathrm{ZnCuAl})_{2}$ appear as discrete platelet particles that are semi coherent with the matrix, which is known to populate within the grains, and $\eta$ is the pseudostable, non-coherent form of the same phase appearing as rods or plates, which is known to populate along the grain boundary [15].

Figure 6 also shows that the highest hardness point in the hardness profiles were not always reached at the nugget zone. Previous work [6] has reported grain refining of the matrix, as well coarsening and dissolution of the strengthening precipitates during the thermal cycle of the FSP. It has also been reported that the Al2O3 particles restrict grain boundary migration during FSP. It has been also shown that the major contributions to hardness of the surface composite layers fabricated by FSP are 1) the fine grain size of the Al matrix, and 2) the Orowan strengthening due to the reinforcement particles [16]. This means that the observed increase in hardness (observed in this work) after FSP without nano particles addition and before heat treatment is attributed to a number of causes: finer grain sizes and work hardening effect [17]. Whereas, the increase in hardness associated with nano particles addition can be attributed to Orawan strengthening effect [17], where thermal mismatch occurs between hard ceramic particles and the soft matrix. However, the observed retreat of the effect of heat treatment on the nanodispersed surface (observed in this work) may be attributed to the effect of alumina particles on hindering the formation of the precipitates which are responsible for the T6 hardening effect. Also, possible earlier formation of these precipitates during FSP may disturb the natural aging sequence, as the formation of a more stable phase will hinder the formation of the less stable one [18]. However, the most significant effect of adding the nanoparticles is their effect on delaying the softening effect after prolonged exposure at the aging temperature observed after $36 \mathrm{hrs}$.

\section{Impact Toughness of Friction Stir Processed Zone}

Charpy impact notch-less samples were prepared perpendicular to the nugget zone such that the FSP zone is in the middle as shown in Figure 7. The tests were conducted on notch-less specimens in order to evaluate the pure material effect of microstructure alone without introducing a notch effect. The specimens were hit on the FSP zone perpendicular to the nugget. It was observed that the specimens broke in the TMAZ zone (Fig. 8). Figure 8 shows that all nanodispersed samples fractured with a sharp notch effect (resulting from the groove containing the nanoparticles). 
Figure 9 shows the change in impact toughness for all samples. It can be seen that generally the monolithic samples without nanodispersion had higher impact toughness (154-180J), compared to those with nanoparticles and aged for the same time (103-134J). This is explaind by the notch induced effect of the nanoparticlescontaining grooves made at the samples before friction stir processing. The highest impact toughness was obtained for both with and without nanodispersion after 48hrs aging. Figure 9 also shows that the maximum toughness was obtained for both the monolithic and nanodispersed alloys after aging for 48 hours: 134 and $181 \mathrm{~J}$, respectively. This is associated with the highest hardness values (Fig. 10), also shown for this condition. After 60 hours aging, significant grain growth occurred for both monolithic and nanodispersed alloys which caused a drop in the impact toughness. However, the rise in hardness continued in the monolithic alloy due to intense precipitation of the $\mathrm{Mg}(\mathrm{ZnCuAl}) 2$ particles. The improved impact toughness observed for the nanodispersed sample after aging for 48 hours is attributed to the presence of the pseudostable non-coherent form of precipitates. It has been shown that ultrafine grain (UFG) structures of 7075 obtained by various techniques possesses a relatively small volume fraction of GP zones, in favour of the metastable $\eta$ ' structure that precipitates in the grain interiors.

The optimized hardness-impact toughness was achieved for the 48hrs alloy for both with (198 HV-134 J) and without (213 HV-181 J) nanodispersed conditions. Though the friction stir processed alloy without nanodispersion showed higher values of both hardness and impact toughness, the nanodispersed alloy exhibited features of ductile fracture of the surface.

\section{CONCLUSIONS}

Friction stir processing may be utilized to develop surface-nanocomposites with $\mathrm{Al}_{2} \mathrm{O}_{3}$ nanodispersions embedded in the matrix. The new surface nanocomposites showed enhancement in the hardness of the surface of A7075- to almost double of the starting material after 4 passes FSP with incorporating nano-alumina particles before and after T6 heat treatment up to 36 aging hours. Friction stir processing of AA7075 alloy without and with the addition of Al2O3 nanoparticles produces hard surfaces of optimized hardness-impact toughness. Hardness-impact correlations for both with (198 HV-134 J) and without (213 HV-181 J) nanodispersed particles was achieved after $48 \mathrm{hrs}$ aging at $1200 \mathrm{C}$, following solution treatment at $5150 \mathrm{C}$ for $1 \frac{1 / 2}{\mathrm{hrs}}$.

\section{ACKNOWLEDGMENT}

The science and technology development fund (STDF), Ministry of scientific research (Egypt) is deeply acknowledged for funding this work with grant number 3926.

\section{REFERENCES}

[1] Mishra, R.S., Ma, Z.Y., "Friction Stir Welding and Processing," Materials Science and Engineering, v. 50, p. 1-78, 2005.

[2] Rosmark, B. P., "Friction Stir Processing Parameters and property Distributions in Cast Nickel Aluminum Bronze," diss., Naval Postgraduate School, 2006. 
[3] W.M. Thomas, E.D. Nicholas, J.C. Needham, M.G. Murch, P. Templesmith, and C.J. Dawes: G.B. Patent Application No. 9125978.8, Dec. 1991

[4] Lee CS, Li H, Chandel RS. "Vacuum-free diffusion bonding of aluminium metal matrix composite. J Mater Process Technol", 1999;89(90):326e30.

[5] Sudhakar, I., V. Madhu., Madhusudhan Reddy G., Srinivasa Rao K., "Enhancement of wear and ballistic resistance of armour grade A7075 Aluminum alloy using friction stir processing" Defense Technology Volume 11, Issue 1, March 2015, Pages 10-17, 2015.

[6] Bozorg, S.F.K., Zarghani, A.S., and Zarei-Hanzaki, A.; "Fabrication of Nano- Composite Surface Layers on Aluminium Employing Friction Stir Processing Technique", CP1217, Interntaional conference on advancement of materials and nanotechnology 2007(ICAMN 2007).

[7] Mahmoud, E. R. I. , Takahashi, M., Shibayanagi, T. and Ikeuchi, K.; "Effect of friction stir processing tool probe on fabrication of SiC particle reinforced composite on aluminium surface", Science and Technology of Welding and Joining (2009) VOL 14 NO 5, P. 713.

[8] Madhusudhan Reddy G, Mohandas T.; "Ballistic performance of high strength low-alloy steel weldments", J Mater Process Technol 1996; 57:23e30.

[9] Madhusudhan Reddy G, Mohandas T, Tagore GRN.; "Weldability studies of high strength low- alloy steel using austenitic fillers", J Mater Process Technol 1995; 49:213e28

[10] Demir Teyfik, Ubeyli Mustafa, Orhan Yıldırım R.; "Investigation on the ballistic impact behavior of various alloys against $7.62 \mathrm{~mm}$ armor piercing projectile", Mater Des 2008;29:2009e16.

[11] Backman EM, Goldsmith W. "The mechanics of penetration of projectiles into targets", Int J Eng Sci 1978;16:1e99

[12] Corbett GG, Reid SR, Johnson W.; "Impact loading of plates and shells by free-flying projectiles: a review", Int J Impact Eng 1996;18:141e230.

[13] Ahmed, M.M.Z, M. Refat, I. El-Mahallawi "Manufacturing of Nano-Surface AA7075 Composites By Friction Stir Processing " Characterization of Minerals, Metals, and Materials 2014, TMS2014, Jon Wiley\& Sons

[14] Reda, Y., Abdel-Karim, R., and Elmahallawi, I.; "Improvements in mechanical and stress corrosion cracking properties in Al-alloy 7075 via retrogression and reaging", Materials Science and Engineering A 485 (2008) 468-475.

[15] J.M. Papazian, "Differential scanning calorimetry evaluation of retrogressed and re-aged microstructures in aluminium alloy 7075", Mater. Sci. Eng. 79 (1986) 97-104.

[16] Zarghani, A.S., Boorg, S.F.K., Hanzaki, A.Z., "Microstructure and mechanical properties of $\mathrm{Al} / \mathrm{Al} 2 \mathrm{O} 3$ surface nano-composite layer produced by friction stir processing", Mater. Sci. Eng. (2009), A500, 8491.

[17] Kashani-Bozorg, S.F., and Jazayeri, K.; Nanoscience and, Nanotechnology, International Conference on Nanoscience andNanotechnology, (NANO- Sci-Tech 2008), edited by M. Rusop and T. Soga, 2009 American Institute of Physics (2009). 
[18] Emani, S. V., Benedyk, J., Nash, P., and Chen, D.; "Double aging and thermomechanical heat treatment of AA7075 aluminum alloy extrusions" J. Mater Sci (2009) 44:6384-6391

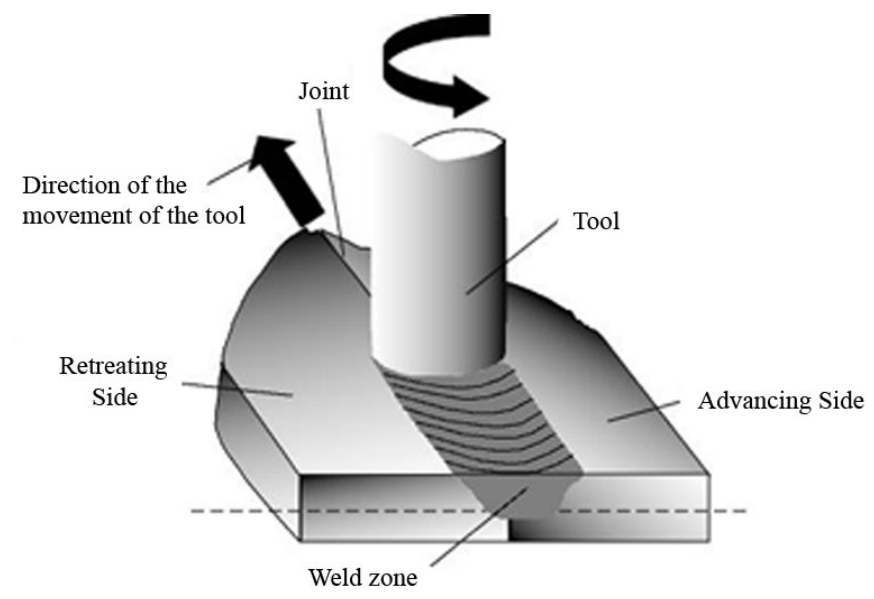

Fig.1: Schematic presentation of the friction stir processing method
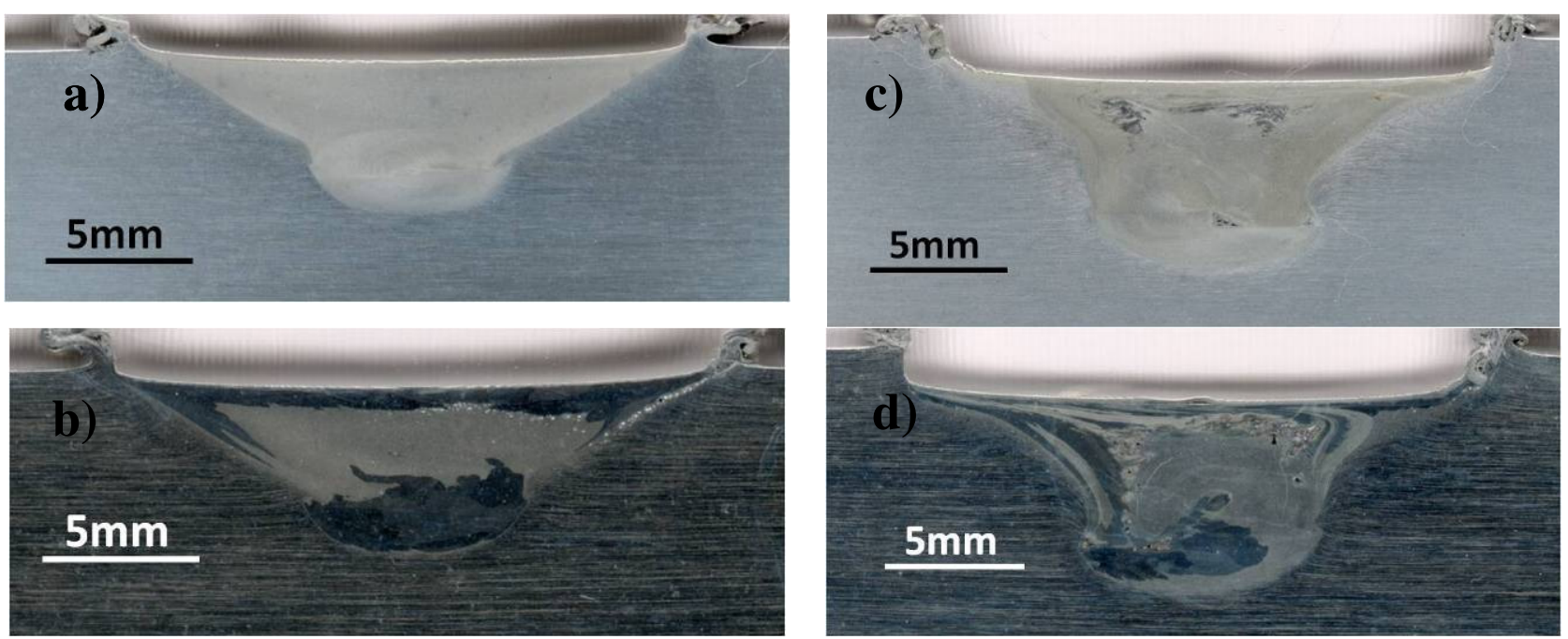

Fig. 2: Optical macrographs of the as friction stir processed AA7075-O without nano alumina additions in a) and after heat treatment in b), optical macrographs of the as FSPed AA7075-O with nano alumina additions in c) and after heat treatment in d).

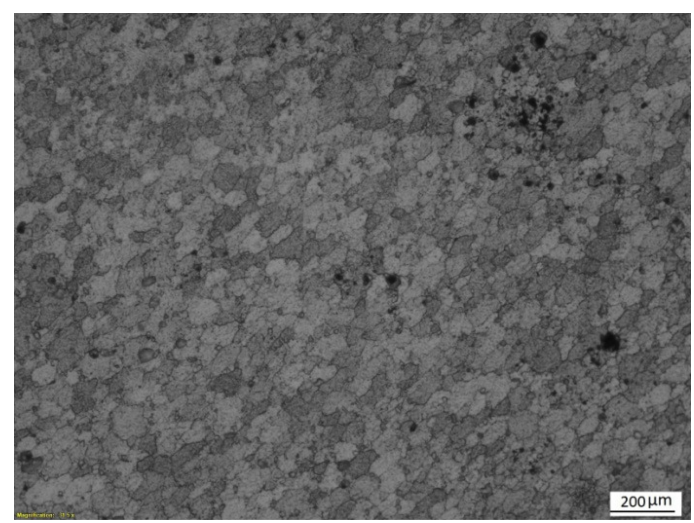

Fig.3: Optical microstructure of the as friction stir processed sample with nano alumina additions inside the NG region. 


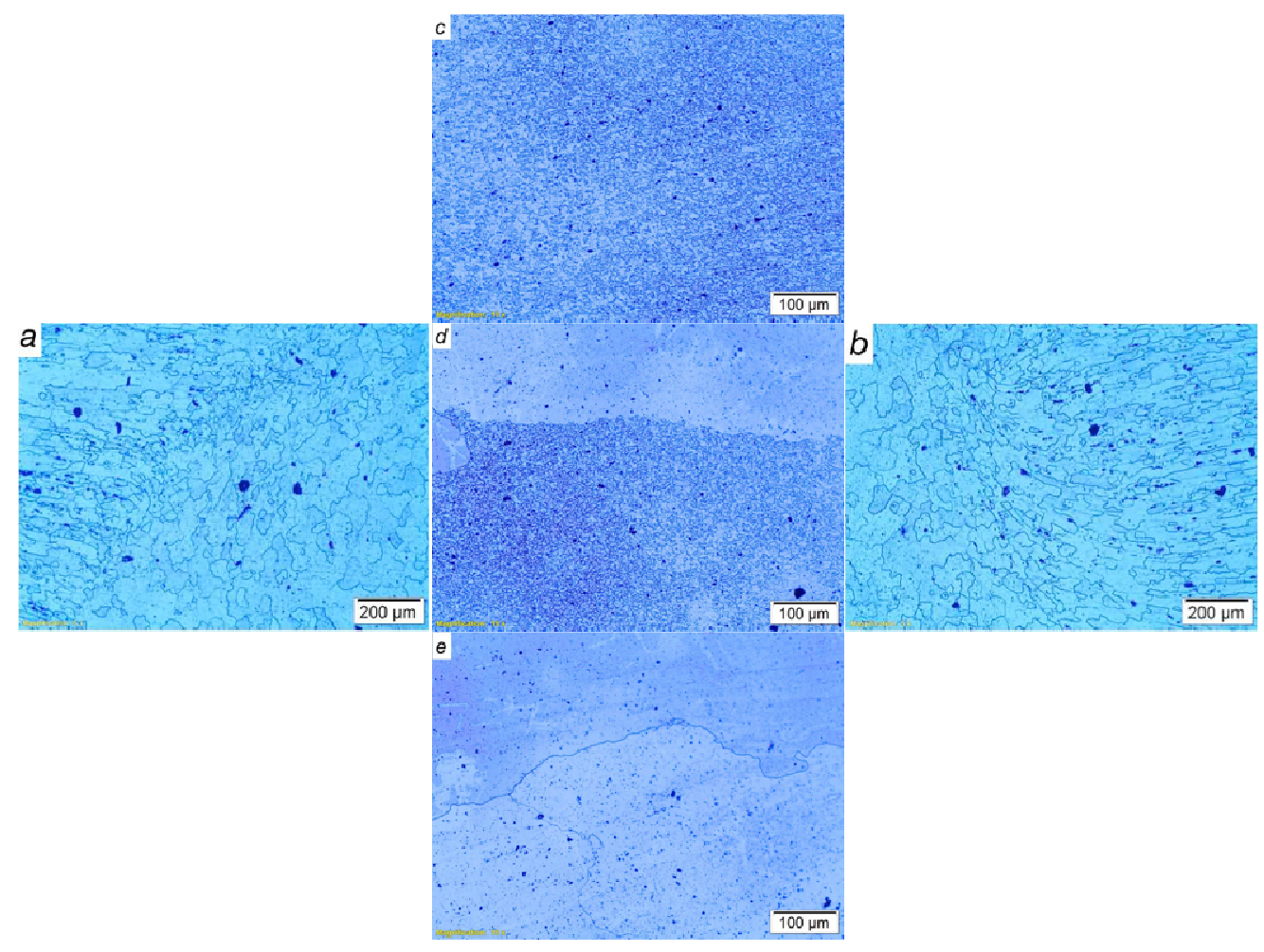

Fig.4: Optical microstructure of the as friction stir processed sample without nano alumina additions after solution treatment at $515 \mathrm{C}$ for $1.5 \mathrm{hrs}$ and aging at $120 \mathrm{C}$ for $24 \mathrm{hrs}$.

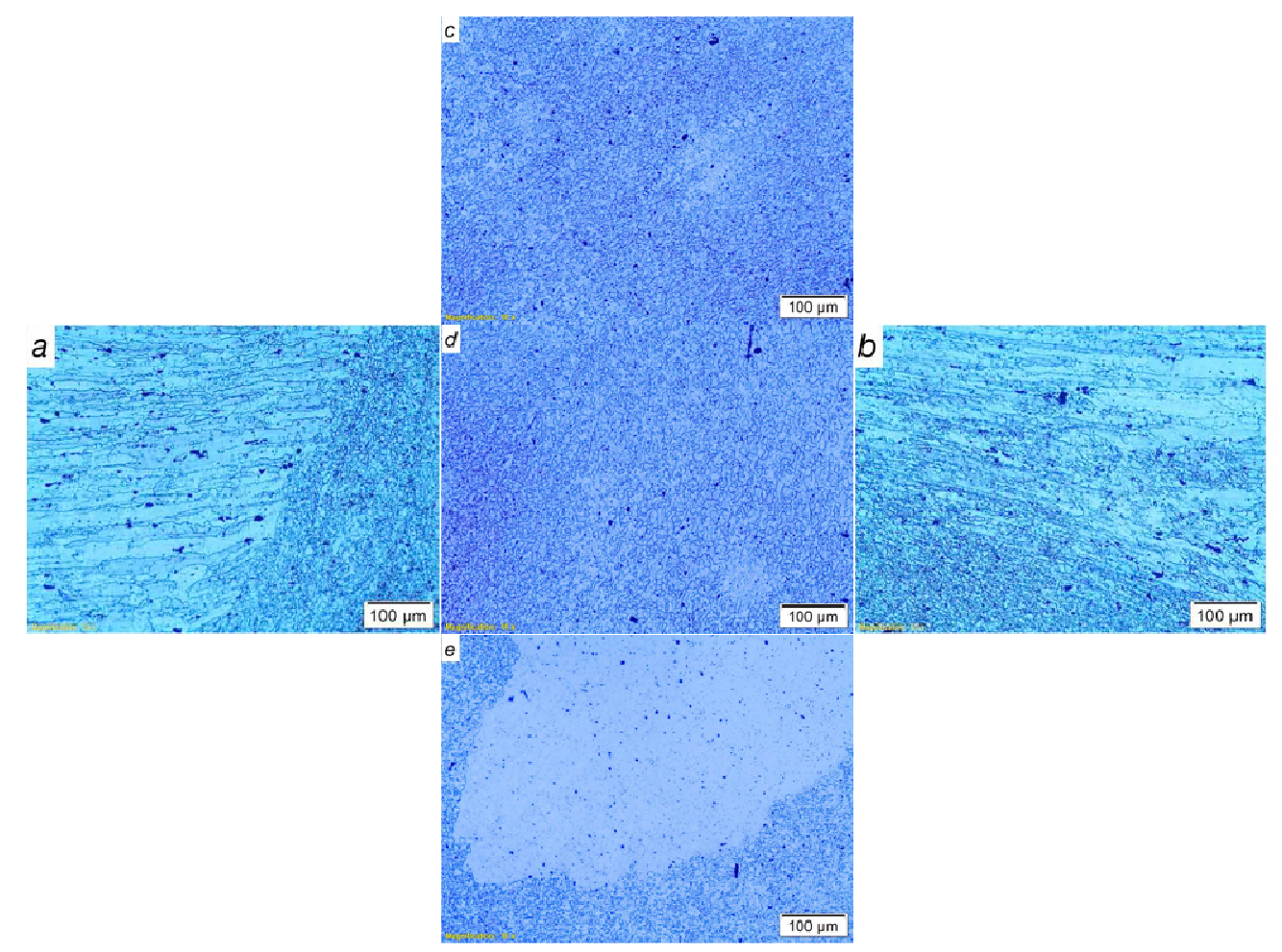

Fig 5: Optical micrograph of microstructures of the as friction stir processed sample AA7075 with nano alumina additions (24hrs). 


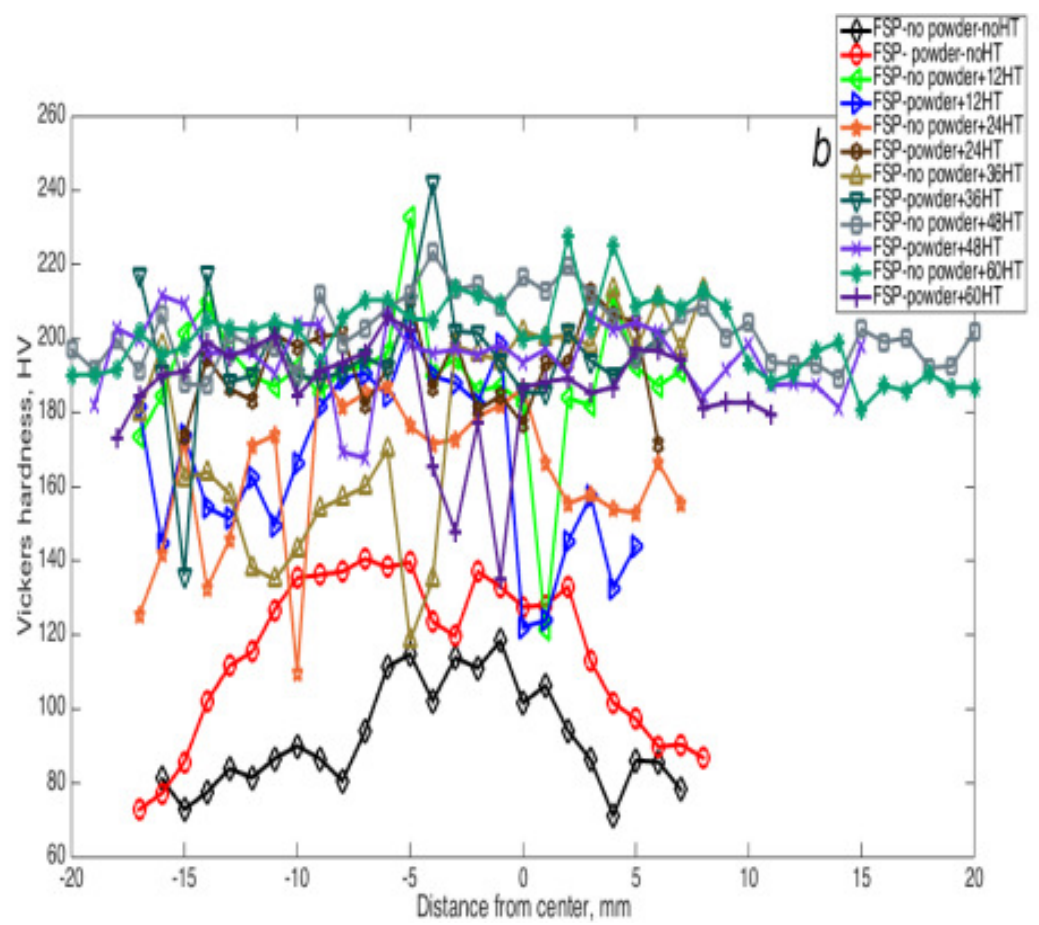

(a)

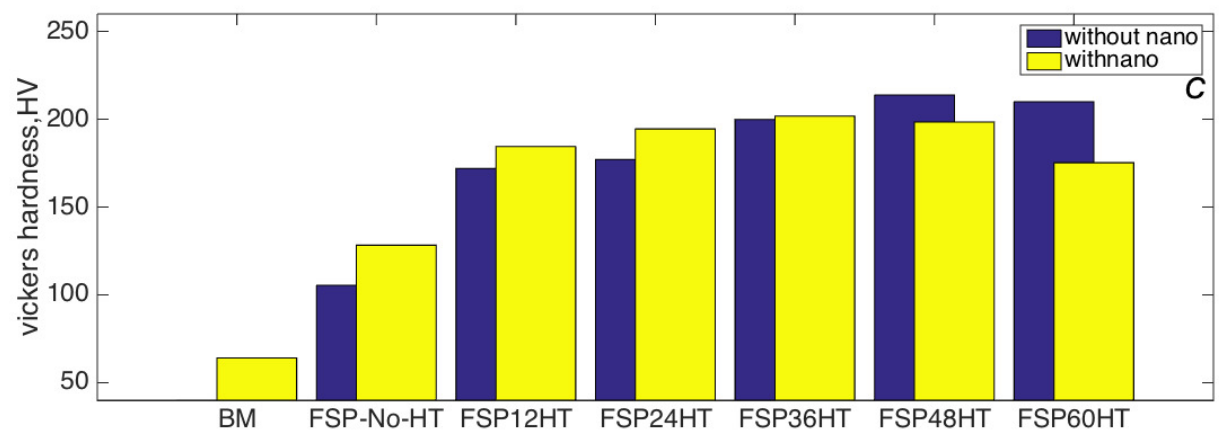

(b)

Fig. 6: a) collective curves for all conditions b) comparison of BM with all conditions.

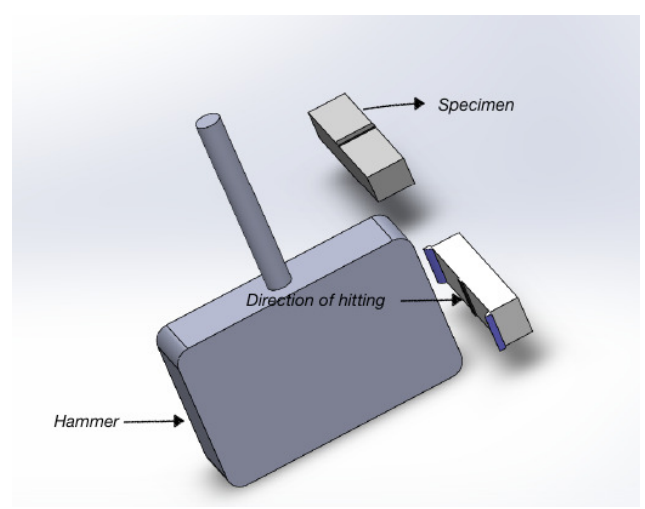

Fig. 7: The impact specimens showing the direction of hitting on the friction stir processed region. 


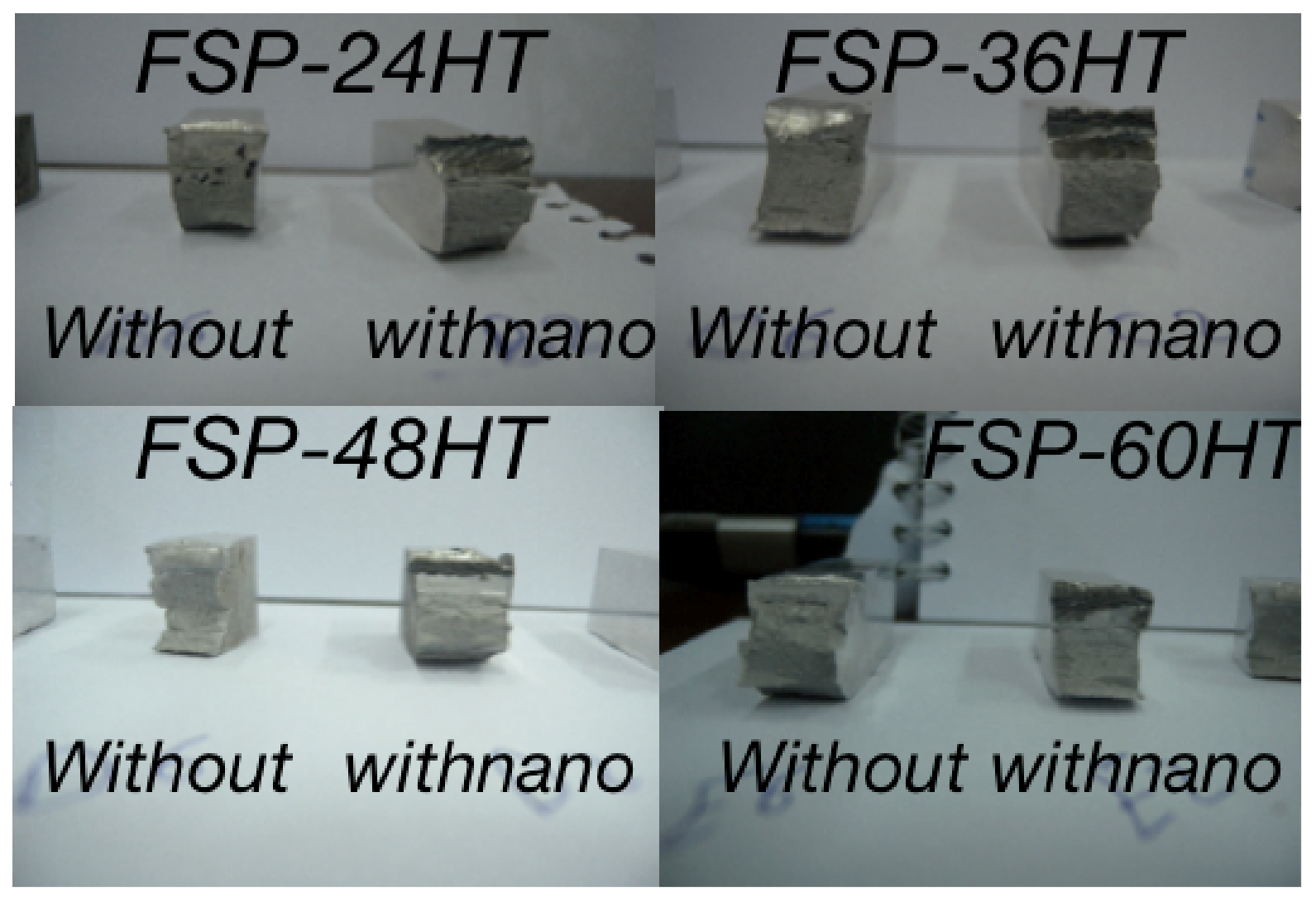

Fig. 8: pictures of the broken samples.

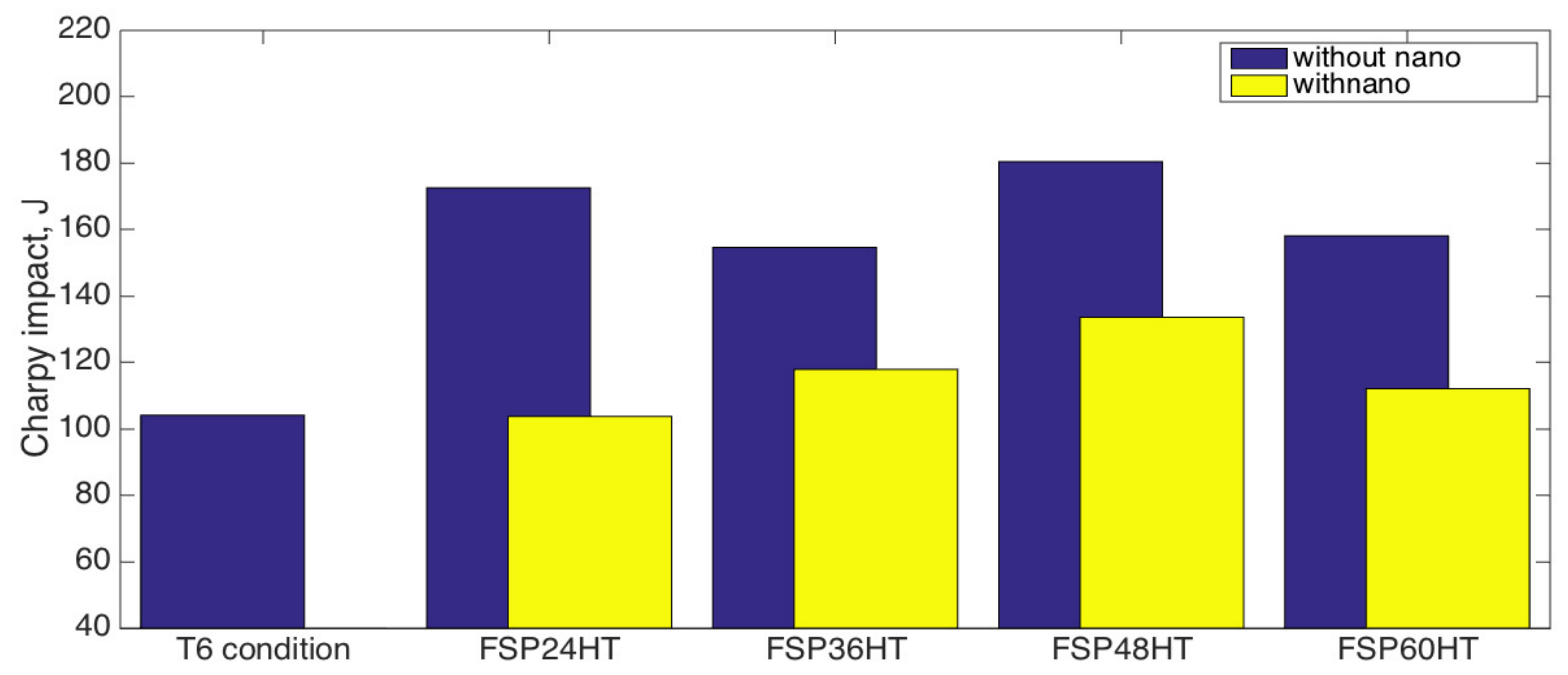

Fig. 9: Impact toughness for all ageing conditions for samples with and without nanodispersion. 


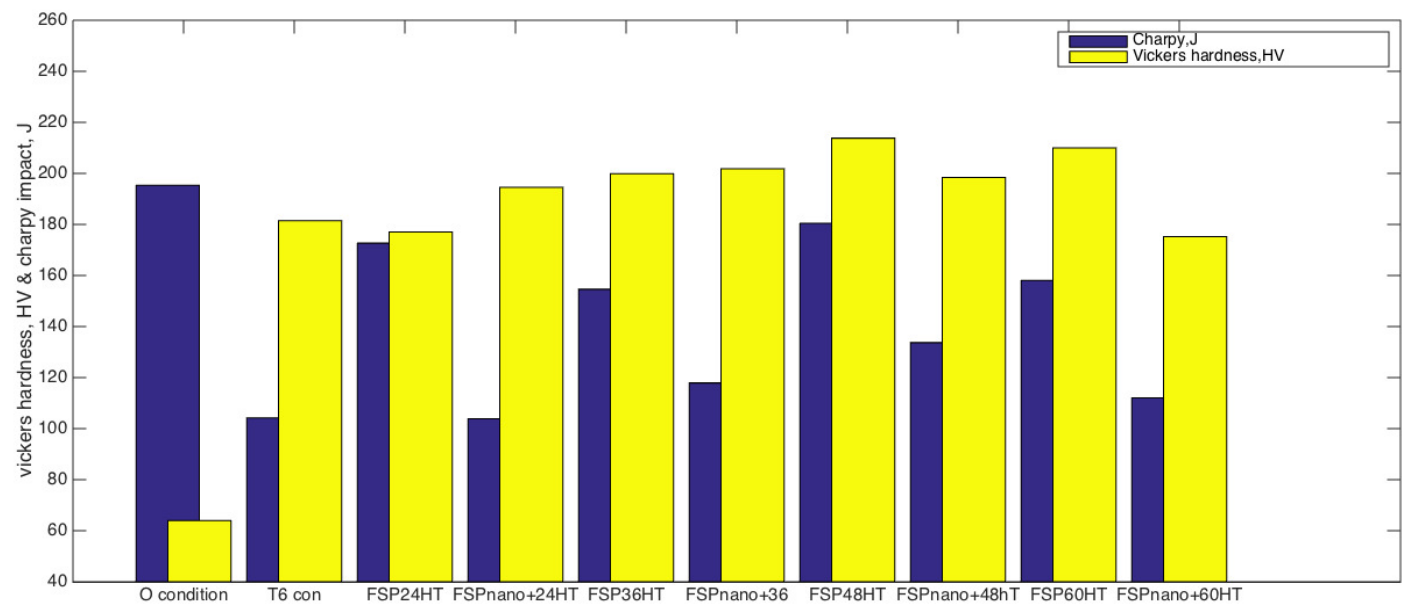

Fig. 10: Impact toughness-average hardness correlation for all ageing conditions. 